\title{
Hemodiyaliz Uygulanan Kronik Hepatit C Hastalarında Ombitasvir/Paritaprevir/ Ritonavir+Dasabuvir Tedavi Sonuçları
}

\section{Ombitasvir/Paritaprevir/Ritonavir + Dasabuvir Treatment Results in Chronic Hepatitis C Patients Undergoing Hemodialysis}

\author{
Duru MISTANOG̃LU ÖZATAG̃̄ (IDD), Pınar KORKMAZ1 (ID), Süleyman COȘGUN² (ID), Petek KONYA³ (IID)
}

\footnotetext{
${ }^{1}$ Kütahya Sag̃ıı Bilimleri Üniversitesi, İnfeksiyon Hastalıkları Anabilim Dalı, Kütahya, Türkiye

${ }^{2}$ Kütahya Sag̃lık Bilimleri Üniversitesi, Gastroenteroloji Anabilim Dalı, Kütahya, Türkiye

${ }^{3}$ Afyon Sag̃lık Bilimleri Üniversitesi, İnfeksiyon Hastalıkları Anabilim Dalı, Afyon, Türkiye
}

Makale atıfı: Mıstanoğlu Özatağ D, Korkmaz P, Coşgun S, Konya P. Hemodiyaliz uygulanan kronik hepatit C hastalarında ombitasvir/paritaprevir/ ritonavir+dasabuvir tedavi sonuçları. FLORA 2021;26(4):736-41.

\section{ÖZ}

Giriş: Hepatit C virüs (HCV) infeksiyonu hemodiyaliz veya periton diyalizi ihtiyacı olan son dönem böbrek hastalığı olan hastalarda sık görülmektedir. Hemodiyaliz uygulanan hastalarda HCV infeksiyonu karaciğer ilişkili ve tüm nedenlere bağlı mortalite riskini arttırmaktadır. Bu nedenle tüm son dönem böbrek hasarı olan hastalarda fibrozis derecesinden bağımsız olarak HCV infeksiyonu tedavisi önerilmektedir. Bu çalışmada hemodiyaliz uygulanan KHC hastalarında paritaprevir/ritonavir/ombitasvir ve dasabuvir (PrOD) tedavisinin etkinliği ve güvenirliliğinin değerlendirilmesi amaçlanmıştır.

Materyal ve Metod: 1 Ocak 2017 - 1 Ekim 2019 tarihleri arasında Infeksiyon Hastalıkları ve Gastroenteroloji Kliniklerinde KHC tanısıla takip edilen ve rutin hemodiyaliz programına alınan hastalar değerlendirildi. Tüm hastalara ait demografik veriler, tedavi yanıtları ve yan etkiler retrospektif olarak medikal kayitlardan değerlendirildi.

Bulgular: Çalışmaya dahil edilen 12 hastanın yaş ortalaması $64.6 \pm 10.4$ idi. Hastaların dokuzu (\%75) erkekti. Tüm hastalara PrOD tedavisi verildi, genotip 1 ve 1 a hastalarında ( $n=4)$ tedaviye ribavirin (200 mg/gün) eklendi. Hastaların sekizinde genotip 1b, ikisinde genotip 1a, ikisinde genotip 1 saptandı. Bir hasta tedavi deneyimliydi. Üç hastada kompanse karaciğer sirozu mevcuttu. Tedavinin 4. haftası virolojik yanıt oranı \%92 idi. Tedaviyi tamamlayan hastalarda $(n=10)$ tedavi bitimi virolojik yanıt oranı \%100 idi. Bu hastalarda Kalıcı Viral Yanıt oranı \%100 idi. En sık görülen yan etkiler çarpıntı ve tansiyon değerlerinde yükselme idi. Yan etkiler nedeniyle iki hasta tedaviyi tamamlayamadı. Sonuç: Hemodiyaliz programındaki hastalarımızda HCV infeksiyonunun tedavisinde PrOD rejimi kolay tolere edilebilen ve virolojik yanıtı yüksek bir tedavi seçeneği sunmaktadır.

Anahtar Kelimeler: Hemodiyaliz; Hepatit C; Ombitasvir; Paritaprevir; Dasabuvir 


\title{
ABSTRACT \\ Ombitasvir/Paritaprevir/Ritonavir + Dasabuvir Treatment Results in Chronic Hepatitis C Patients Undergoing Hemodialysis
}

\author{
Duru MISTANOG̃LU ÖZATA $\tilde{G}^{1}$, PInar KORKMAZ1', Süleyman COȘGUN² Petek KONYA³
}

\footnotetext{
${ }^{1}$ Department of Infectious Diseases, Kütahya Health Sciences University, Kütahya, Turkey

2 Department of Gastroenterology, Kütahya Health Sciences University, Kütahya, Turkey

${ }^{3}$ Department of Infectious Diseases, Afyon Health Sciences University, Afyon, Turkey
}

Introduction: Hepatitis C virus (HCV) infection is common in patients with end-stage renal disease who need hemodialysis or peritoneal dialysis. HCV infection increases the risk of liver-related and all-cause mortality in patients undergoing hemodialysis. Therefore, treatment of HCV infection is recommended in all patients with end stage kidney damage regardless of the degree of fibrosis. In this study, we aimed to evaluate the efficacy and safety of paritaprevir/ritonavir/ombitasvir and dasabuvir (PrOD) treatment in CHC patients undergoing hemodialysis.

Materials and Methods: Patients who were followed up with the diagnosis of KHC in the Infectious Diseases and Gastroenterology Clinics between January 2017 and October 2019 and were included in routine hemodialysis program were evaluated. Demographic data of all patients were retrospectively evaluated from medical records in terms of treatment responses and side effects.

Results: Mean age of 12 patients included in the study was $64.6 \pm 10.4$ years. Nine (75\%) of the patients were males. PrOD treatment was given to all patients, ribavirin $(200 \mathrm{mg} /$ day) was added to the treatment in patients with genotype 1 and $1 \mathrm{a}(n=4)$. Genotype $1 \mathrm{~b}$ was found in eight patients, genotype 1 a in 2, genotype 1 in two patients. One patient was experienced in treatment. Three patients had compensated liver cirrhosis. At the $4^{\text {th }}$ week of treatment, the virological response rate was $92 \%$. The virological response rate at the end of treatment was $100 \%$ in patients who completed the treatment $(n=10)$. Sustained Virological Response rate in these patients was $100 \%$. The most common side effects were palpitations and rising of blood pressure values. Two patients could not complete the treatment due to side effects.

Conclusion: PrOD regimen offers an easily tolerated treatment option with high virological response in the treatment of HCV infection in our patients under the hemodialysis program.

Key Words: Hemodialysis; Hepatitis C; Ombitasvir; Paritaprevir; Dasabuvir

\section{Giriș}

Hepatit $\mathrm{C}$ virüs (HCV) infeksiyonu hemodiyaliz veya periton diyalizi ihtiyacı olan son dönem böbrek hastalığı olan hastalarda sık görülmektedir $^{[1]}$. Türk Nefroloji Derneği 2018 verilerine göre hemodiyalize giren hastaların \%3.42'sinde anti-HCV pozitifliği mevcuttur ${ }^{[2]}$. Hepatit $\mathrm{C}$ virüs infeksiyonu böbrek hasarı ile iliskili olup $\mathrm{HCV}$ infeksiyonu olan hastaların \%10-16'sında böbrek hastalığı gelișmektedir ${ }^{[3]}$. Hemodiyaliz uygulanan hastalarda HCV infeksiyonu karaciğer ilișkili ve tüm nedenlere bağlı mortalite riskini arttırmakta$\mathrm{d}_{1}{ }^{[1]}$. Son dönem böbrek hastalığı olan hastalarda siroz, hepatosellüler karsinoma ve karaciğer iliskili mortalite $\mathrm{HCV}$ infeksiyonu olmayan son dönem böbrek hastalarına göre daha fazladır ${ }^{[4]}$.

Direkt etkili antiviral (DEA) tedaviler öncesinde hemodiyaliz uygulanan hastalarda HCV infeksiyo- nu tedavisinde standart tedavi pegile interferon (ribavirinli/ribavirinsiz) idi. Ancak bu tedavinin yan etkilerinin cokluğu ve etkinliğinin düşük olmas1 önemli dezavantajlardı ${ }^{[5]}$. Direkt etkili antiviral tedavi alan ve hemodiyaliz uygulanan $\mathrm{KHC}$ hastalarında KVY oranları \%94-100'e ulasmaktadır. Ciddi renal hasarı olan veya hemodiyaliz uygulanan hastalarda sofosbuvir içermeyen rejimler önerilmektedir. Bu tedaviler paritaprevir/ritonavir/ ombitasvir ve dasabuvir (PrOD), grazoprevir ve elbasvir, glecaprevir ve pibrentasvir kombinasyonlarıdır $^{[1]}$. Bu calıșmada hemodiyaliz uygulanan KHC hastalarında PrOD tedavisinin etkinliği ve güvenirliliğinin değerlendirilmesi amaçlanmıștır.

\section{MATERYAL ve METOD}

1 Ocak 2017 - 1 Ekim 2019 tarihleri arasinda İnfeksiyon Hastalıkları ve Gastroenteroloji Kliniklerinde $\mathrm{KHC}$ tanısıla takip edilen ve rutin 
Tablo 1. PrOD tedavisi hastaların başlangıç ve tedavi sonu laboratuvar değerleri

\begin{tabular}{lcc} 
Laboratuvar değerleri & Tedavi öncesi & Tedavi sonu \\
\hline ALT $(\mathrm{IU} / \mathrm{mL})$ & $32.4 \pm 12.8$ & $16.8 \pm 7.17$ \\
AST $(\mathrm{IU} / \mathrm{mL})$ & $29.6 \pm 12.8$ & $19.6 \pm 5.24$ \\
Hemoglobin $(\mathrm{g} / \mathrm{dL})$ & $12.3 \pm 1.22$ & $11.7 \pm 1.58$ \\
Trombosit $\left(10^{3} / \mu\right)$ & $162 \pm 39$ & $163 \pm 52.5$ \\
Albümin $(\mathrm{mg} / \mathrm{dL})$ & $3.7 \pm 0.5$ & $3.8 \pm 0.7$ \\
Total bilirubin $(\mathrm{mg} / \mathrm{dL})$ & $0.54 \pm 0.1$ & $0.57 \pm 0.17$ \\
HCV RNA $(\mathrm{IU} / \mathrm{mL})$ & $1.37 \pm 2.36 \times 10^{6}$ & Negatif
\end{tabular}

hemodiyaliz programına alınan hastalar değerlendirildi. Tüm hastalara ait demografik veriler, tedavi yanıtları ve yan etkiler açısından retrospektif olarak medikal kayıtlardan değerlendirildi. Çalıșma için lokal etik komiteden 08.01.2021 tarih 2011-KAEK-2 karar numarası ile onay alınd. Anti-HCV kemilüminesan mikropartikül immünoassay yöntemiyle Liaison (Diasorin, Saluggia, Italy) kullanılarak calıșıldı. Hastalarda polimeraz zincir reaksiyonu yöntemiyle $\mathrm{HCV}$ RNA, Qiagen, Artus HCV RG TR-PCR (Hilden, Germany) kullanılarak (alt limit $34 \mathrm{IU} / \mathrm{mL}$ ) calıșıldı. HCV genotiplendirme Geno-Sen's Rotorgene Real time PCR, (Corbett Research, Australia) ile calıșıldı. Hastalara bașlanan PrOD tedavisi ile kullandıkları ilaçlar arasındaki ilaç-ilaç etkileșimi ilaç etkileșim sitesi: https://www.drugs.com/drug_interactions.html adresinden kontrol edildi ${ }^{77]}$.

İstatiksel analizde IBM SPSS Statistics for Windows. Version 20.0 programı kullanıldı. İstatistiksel olarak gerekli tanımlayıcı bilgiler kategorik değiskenlerde sıklık ve yüzde olarak verilirken, sürekli değișkenler için ortalama ve standard sapma olarak verilmiștir. $\mathrm{p}<0.05$ düzeyi istatistik olarak anlamlı kabul edilmiștir.

\section{BULGULAR}

Çalıșmaya dahil edilen 12 hastanın yaș ortalaması $64.6 \pm 10.4$ idi. Hastaların dokuzu (\%75) erkekti. En sık eșlik eden hastalıklar diabetes mellitus $(n=5)$, hipertansiyon $(n=7)$, KOAH $(n=$ 4) ve ritm bozukluğu $(n=4)$ idi. Tüm hastalara PrOD (Viekirax, $75 \mathrm{mg} / 50 \mathrm{mg} / 12.5 \mathrm{mg}$ film tablet, Abbvie Deuthsland $\mathrm{GmbH}$ \& Co. KG, Wiesbaden, Almanya) 1x2 ve dasabuvir (Exviera, $250 \mathrm{mg}$ film tablet Abbvie Deuthsland $\mathrm{GmbH}$ \& Co. KG, Wiesbaden, Almanya) $2 \times 1$ tedavisi verildi, genotip 1 ve 1 a hastalarında $(n=4)$ tedaviye ribavirin (200 mg/gün) eklendi. Hastaların 8 'inde genotip 1b, 2'sinde genotip 1a, 2'sinde genotip 1 saptand. Bir hasta tedavi deneyimliydi. Üc hastada kompanse karaciğer sirozu mevcuttu. Bașlangıc HCV-RNA değerleri ortalama $1.37 \pm$ $2.36 \times 10^{6} \mathrm{IU} / \mathrm{mL}$ idi. Hastalara ait bașlangıc ve tedavi sonu laboratuvar değerleri Tablo 1'de verilmiștir. Tedavinin 4 . haftası virolojik yanıt oranı \%92, tedaviyi tamamlayan hastalarda $(n=10)$ tedavi bitimi virolojik yanıt oranı \%100 idi. Bu hastalarda KVY oranı \%100 tespit edildi.

Yan etki olarak ribavirin alan 4 hastada hemoglobin düșusüu görüldü, hiperbilirubinemi ve aminotransferaz yüksekliği hiçbir hastada görülmedi. En sık görülen yan etkiler carpıntı ve tansiyon değerlerinde yükselme idi, PrOD tedavisi sırasında en sık görülen yan etkiler Tablo 2'de verilmiștir. Tedavi bașlangıcında hastaların kullandığı ilaçlar ile PrOD tedavisi arasında tüm hastalarda en az bir ilac için orta etkileșim mevcuttu. Altı hastada en az bir ilaç için major etkileșim vardı iki

\begin{tabular}{|c|c|}
\hline Yan etki & n (\%) \\
\hline Çarpıntı & $7(58.3)$ \\
\hline Tansiyon değerlerinde kötüleşme & $5(41.6)$ \\
\hline Uykusuzluk & $5(41.6)$ \\
\hline Halsizlik & $4(33.3)$ \\
\hline Nefes darlığı & $4(33.3)$ \\
\hline Kaşıntı & $3(30)$ \\
\hline Bulantı & $3(30)$ \\
\hline İştahsızlık & $3(30)$ \\
\hline
\end{tabular}


hastada lercadipinine, iki hastada lercadipinine ve amiadorone, iki hastada amiadorone, bir hastada tamsulosin ve amiadorone ile ritonavir arasinda major etkileșim mevcuttu. Bu hastaların tümünde ilaç değișikliği yapıldı. Beș hastada orta etkileșim gösteren ilac/ilaçlar PrOD tedavisi sırasında yan etkiler nedeniyle değiștirildi. Yan etkiler nedeniyle iki hasta tedaviyi tamamlayamad.. Bu hastalardan ilki carpıntı, nefes darlığı gibi yan etkileri tolere edememesi nedeniyle hekime haber vermeden ilaca ara vermesi nedeniyle 12 haftalık tedaviyi tamamlayamadı, toplam 8 haftalık tedavi sonunda virolojik yanıt alındı, takiplerinde KVY alınamadı. İkinci hasta toplam 6 haftalı tedavi sonunda miyokard infarktüsü geçirmesi sonrası bașlanan tedavi ile PrOD tedavisi arasında majör etkileșim olması üzerine PrOD tedavisi kesildi. 12. hafta sonu virolojik yanıt ve KVY elde edildi.

\section{TARTIȘMA}

Avrupa Karaciğer Çalıșmaları Derneği (EASL) $\mathrm{HCV}$ ile infekte kronik böbrek hastalığı olan tüm hastalarda fibrozis derecesinden bağımsız olarak antiviral tedavi önermektedir. Bu hastalarda erken tanı ve tedavinin uzun dönem sonuclarında hem karaciğer hem de böbrekte kötü klinik gidiși önleyeceği belirtilmektedir ${ }^{[1,8]}$. Direkt etkili antiviraller ülkemizde 18 Haziran 2016 tarihinden itibaren kullanıma girmistir. Hemodiyaliz hastaları için EASL 2015 yll önerilerinde simeprevir, daklatasvir ve PrOD tedavilerinin kullanilabileceği belirtilmiștir ${ }^{[9]}$. Amerikan Karaciğer Hastalıkları Araștırma Derneği (AASLD) 2015 yılı önerilerinde ciddi renal hasarı olan genotip 1 nonsirotik hastalarda PrOD tedavisi önerilmektedir ${ }^{[10]}$.

Ciddi renal hasarı $(e$ GFR $\leq 30 \mathrm{~mL} / \mathrm{min} / 1.73$ $\mathrm{m}^{2}$ ) olan hastalarda EASL, AASLD ve Böbrek Hastalıkları: Küresel Sonuçların İyileștirilmesi (KDIGO) önerilerinde ise tüm genotiplere etkili glecaprevir ve pibrentasvir kombinasyonunu veya grazoprevir ve elbasvir kombinasyonunu önermektedir. Ciddi renal hasarı olan genotip $1 b$ hastaları için grazoprevir ve elbasvir kombinasyonu veya PrOD önerilen tedavi seçenekleridir ${ }^{[1,8,11]}$. Glecaprevir ve pibrentasvir kombinasyonu ülkemizde 05.07.2018'de yayınlanan Sağlık Uygulama Tebliği (SUT) ile kullanıma girmis, ancak genotip 1a ve b'de hastalarda geri ödeme almamıstır.
$\mathrm{Bu}$ nedenle hastalarımızın tümüne güncel rehber önerileri doğrultusunda PrOD tedavisi bașlanmıștır.

Ciddi renal hasarı olan $\mathrm{KHC}$ hastalarında DEA tedavisine ait gerçek yașam verileri değerlendirildiğinde KVY oranlarının \%92.6-100 olduğu görülmüștür ${ }^{[12-17]}$. Ülkemizden bildirilen ve ciddi renal hasarı olan $\mathrm{KHC}$ hastalarına ait gercek yașam verileri içeren çalıșmalar değerlendirildiğinde hastaların PrOD tedavisi ile KVY oranlarının literatürle uyumlu olduğu görülmüștür. Bu çalıșmalardan ilkinde Yaras ve arkadașları toplam 25 ciddi renal hasarı olan $\mathrm{KHC}$ hastasinda PrOD tedavisi ile KVY \%100 olarak bildirmișlerdir ${ }^{[5]}$. Sarı ve arkadașlarının çalıșmasında ise toplam 13 hasta değerlendirilmiș ve KVY hastaların tümünde elde edilmiștir ${ }^{[18]}$. Etik ve arkadașları calıșmasında ise ciddi renal hasarı olan ve böbrek transplant alıcisı olan toplam 18 hastada KVY ciddi renal hasarı olanlarda \%94, böbrek transplant alıcilarında \%92 olarak bildirilmiștir ${ }^{[19]}$. Tatar ve arkadașlarının calıșmasında toplam 33 hastada KVY oranı \%100'dür ${ }^{[20]}$. Örmeci ve arkadașlarının çlıșmasında ise ciddi renal hasarı olan toplam 75 hastada (53 hemodiyaliz programında) KVY \%96 olarak bildirilmiștir ${ }^{[21]}$. Benzer olarak çalıșmamızda PrOD tedavisini tamamlayan tüm hastalarımızda KVY elde edilmistir.

Interferon tedavisine göre DEA ilaçlar yalnızca KVY bakımından üstün değil, aynı zamanda kullanım kolaylığı, kısa süreli tedavi sağlaması, iyi tolere edilmeleri, düsuik yan etki profili ve yönetilebilir ilaç-ilac etkileșimleri nedeniyle de üstünlük sağlamaktadır ${ }^{[20,22]}$.

Hemodiyaliz programındaki $\mathrm{HCV}$ ile infekte hastalar birçok eșlik eden hastalıkları ve buna bağlı olarak coklu ilaç kullanımı olan hasta grubunu temsil etmektedir. Bu nedenle bu hasta grubunda olası ilaç etkileșimlerine göre tedavi düzenlenmeli, tedavi ve olası yan etkiler iyi anlatılarak multidisipliner bir yaklașım sağlanmalıdır ${ }^{[22]}$. Ciddi renal hasarı olan PrOD tedavisi alan hastalara ait calıșmalar değerlendirildiğinde en sık görülen yan etkiler Tatar ve arkadașları calıșmasında yorgunluk, baș ağrısı, eklem ağrısı, kașıntı, karın ağrısı ve iștahsızlık olarak bildirilmiștir. Hastalarda aminotransferaz yüksekliŏi gelișmemiș, takipte ilk 2 hafta sonrasında hiperbilirubinemi saptanmamıș- 
tır ${ }^{[20]}$. Sarı ve arkadaslarının calıșmasında en sık görülen yan etki halsizlik ve iștahsızlık olup, ilacın kesilmesini gerektiren bir yan etki saptanmamıştır ${ }^{[18]}$. Yaras ve arkadașlarının çalıșmasında yorgunluk, kașıntı, tansiyon değerlerinde kötüleșme en sik yan etkiler olup, tedavi yan etkiler nedeniyle hiçbir hastada kesilmemiștir [5]. Calıșmamızda hastalarımızda karșılaștığımız yan etkiler benzerdir. Yalnızca astım tanısı olan bir hastamız gelișen nefes darlığı ve carpıntı sikayetlerini tolere edememesi nedeniyle ilacını aralıklı kullanmıs olması nedeniyle 12 haftalık tedavisini tamamlayamamıstır.

Sonuc olarak; hepatit $\mathrm{C}$ virüü tedavisinde bugün kullanımda olan DEA tedavileri hem kolay tolere edilmesi hem de yüksek KVY sağlaması bakımından hastaların tedavisinde yeni bir çı̆̆ır açmıștır. Calıșmamızda hasta sayısı sınırlıdır. Hasta grubunda yüksek KVY elde edilmesi ve ilacin iyi tolere edilmesi söz konusudur. Eșlik eden hastalıkları ve buna bağlı coklu ilaç kullanımları olan, zorlu hasta grubu hemodiyaliz hastalarında DEA tedavileri, HCV'nin etkin bir sekilde edilmesini sağlaması açısından önemlidir.

\section{ETIK KURUL ONAYI}

Calıșma için, Afyonkarahisar Sağlık Bilimleri Úniversitesi Klinik Araștırmalar Etik Kurulu'ndan onay alındı (Tarih: 08.11.2021, Karar No: 78)

\section{ÇIKAR ÇATIŞMASI}

Yazarlar bu makale ile ilgili herhangi bir cıkar çatıșması bildirmemișlerdir.

\section{YAZAR KATKISI}

Anafikir/Planlama: Tüm yazarlar

Analiz/Yorum: Tüm yazarlar

Veri sağlama: Tüm yazarlar

Yazım: DMÖ, PK

Gözden Geçirme ve Düzeltme: DMÖ, PK

Onaylama: Tüm yazarlar

\section{KAYNAKLAR}

1. EASL Recommendations on Treatment of Hepatitis C 2018European Association for the Study of the Liver. I Hepatol 2018;69:461-511.

2. Türkiye'de Nefroloji, Diyaliz ve Transplantasyon. T.C. Sağıık Bakanlığı ve Türk Nefroloji Derneği Ortak Raporu Erişim tarihi: 15 Mart 2021. Available from:http://www.nefroloji. org.tr/folders/file/REGISTRY_2018.pdf
3. Lens S, Rodriguez-Tajes S, Llovet LP, Maduell F, Londoño MC. Treating Hepatitis C in Patients with Renal Failure. Dig Dis 2017:35:339-46.

4. Lee JJ, Lin MY, Chang JS, Hung CC, Chang JM, Chen CM, et al. Hepatitis $C$ virus infection increases risk of developing end-stage renal disease using competing risk analysis. PLOS One 2014;9:e100790.

5. Yaraş S, Üçbilek E, Özdoğan O, Ateş F, Altıntaş E, Sezgin O. Real-life results of treatment with ombitasvir, paritaprevir, dasabuvir, and ritonavir combination in patients with chronic renal failure infected with HCV in Turkey. Turk I Gastroenterol 2019;30:331-5.

6. Fabrizi F, Dixit $V$, Messa P. Hepatitis $C$ virus and mortality among patients on dialysis: A systematic review and meta-analysis. Clin Res Hepatol Gastroenterol 2019;43:244-54.

7. Drug Interactions Checker-Drugs.com. Erişim tarihi: 15 Mart 2021. Available from: https://www.drugs.com/drug_ interactions.html

8. KDIGO 2018 Clinical Practice Guideline for the Prevention, Diagnosis, Evaluation, and Treatment of Hepatitis C in Chronic Kidney Disease. Erişim tarihi: 15 Mart 2021. Available from: https://kdigo.org/wp-content/uploads/2017/02/ KDIGO-2018-Hep-C-GL.pdf

9. European Association for Study of Liver. EASL Recommendations on Treatment of Hepatitis C 2015. J Hepatol 2015;63:199-236.

10. AASLD-IDSA HCV Guidance Panel. Hepatitis C guidance: AASLD-IDSA recommendations for testing, managing, and treating adults infected with hepatitis $C$ virus. Hepatology 2015;62:932-54.

11. AASLD-IDSA HCV Guidance Panel. Hepatitis C Guidance 2018 Update: AASLD-IDSA Recommendations for Testing, Managing, and Treating Hepatitis C Virus Infection. Clin Infect Dis 2018;67:1477-92.

12. Liu CH, Shih YL, Yang SS, Lin CL, Fang YJ, Chenget $P N$ al. Paritaprevir/ritonavir, ombitasvir plus dasabuvir for East Asian non-cirrhotic hepatitis C virus genotype $1 \mathrm{~b}$ patients receiving hemodialysis. I Gastroenterol Hepatol 2019;34:1977-83.

13. Abad S, Vega A, Hernández E, Mérida E, Sequera P, Albalate $M$, et al. Universal Sustained Viral Response to the Combination of Ombitasvir/Paritaprevir/Ritonavir and Dasabuvir with/without Ribavirin in Patients on Hemodialysis Infected with Hepatitis C Virus Genotypes 1 and 4. Am J Nephrol 2017:45:267-72.

14. Sperl J, Kreidlova M, Merta D, Chmelova K, Senkerikova R, Frankova S. Paritaprevir/Ritonavir/Ombitasvir Plus Dasabuvir Regimen in the Treatment of Genotype 1 Chronic Hepatitis C Infection in Patients with Severe Renal Impairment and End-Stage Renal Disease: a Real-Life Cohort. Kidney Blood Press Res 2018;43:594-605.

15. Lawitz E, Gane E, Cohen E, Vierling J, Agarwal K, Hassanein $T$, et al. Efficacy and Safety of Ombitasvir/Paritaprevir/Ritonavir in Patients With Hepatitis C Virus Genotype 1 or 4 Infection and Advanced Kidney Disease. Kidney Int Rep 2018 9:4:257-66. 
16. Londoño $M C$, Riveiro-Barciela $M$, Ahumada A, Muñoz-Gómez $R$, Roget M, Devesa-Medina MJ, et al. Effectiveness, safety/tolerability of OBV/PTV/r \pm DSV in patients with HCV genotype 1 or 4 with/without HIV-1 co-infection, chronic kidney disease (CKD) stage IIIb-V and dialysis in Spanish clinical practice - Vie-KinD study. PLoS One 2019;14:e0221567.

17. Miyasaka A, Yoshida Y, Yoshida T, Murakami M, Abe K Ohuchi K. The Real-world Efficacy and Safety of Ombitasvir/Paritaprevir/Ritonavir for Hepatitis C Genotype 1. Intern Med 2018;57:2807-12.

18. Sarı N, Köse Ş, Inci A. Hemodiyaliz Uygulanan Kronik Hepatit C Hastalarında Doğrudan Etkili Antiviral Tedavisi Sonuçları. Klimik Derg 2020;33:39-43.

19. Özer Etik D, Suna N, Öcal, Dağı̈̈̈, Çolak T, Hilmioğlu F, et al. Successful Treatment with Direct-Acting Antiviral Agents of Hepatitis $C$ in the Setting of End-Stage Renal Disease. Exp Clin Transplant 2019;17:52-8.

20. Tatar B, Köse Ş, Ergun NC, Turken M, Onlen Y, Y,lmaz Y, et al. Response to direct-acting antiviral agents in chronic hepatitis $C$ patients with end-stage renal disease: a clinical experience. Rev Assoc Med Bras. 2019;65:1470-5.
21. Örmeci $N$, Sezgin $O$, Karaali $R$, Aygen B, Turan $D$, Yaras $S$, et al. Effectiveness of fixed-dose combination of paritaprevir, ritonavir, ombitasvir, and dasabuvir in patients with chronic hepatitis $C$ virus infection and chronic kidney diseases: real-life experiences. Eur / Gastroenterol Hepatol 2019;31:534-9.

22. Erdoğmuş Ş. Hemodiyaliz Hastalarında Kronik Hepatit C Virüs Infeksiyonu: Tedavi Sonuçları ve Ilaç-illaç Etkileşimleri Yönetimi. Ankara Üniversitesi Tıp Fakültesi Mecmuası 2019;72:49-53.

\section{Yazıșma Adresi/Address for Correspondence} Dr. Pınar KORKMAZ

Kütahya Sağlık Bilimleri Üniversitesi, İnfeksiyon Hastalıkları Anabilim Dalı, Kütahya-Türkiye

E-posta: drpinarkor@gmail.com 